\title{
Terapia de suplencia tiroidea: una historia del siglo XIX que aún genera noticias en el siglo XXI
}

\section{Alfredo Jácome Roca}

Médico Internista-Endocrinólogo. Expresidente y Miembro Honorario de la Asociación Colombiana de Endocrinología, Diabetes y Metabolismo, Miembro activo de la Sociedad Colombiana de Historia de la Medicina y Miembro de Número de la Academia Nacional de Medicina de Colombia.

Fecha de recepción: 8/11/2017

Fecha de aceptación: 26/01/2018

$\mathrm{L}$ as tiroidectomías totales del cirujano suizo y ganador del Nobel de Medicina, Teodoro Kocher, llevaron al descubrimiento del hipotiroidismo a finales del siglo XIX, gracias también a la asociación con una serie de informes de diversos investigadores. Félix Semon en 1883 relacionó la clínica de los pacientes totalmente tiroidectomizados (que Kocher denominó "caquexia estrumipriva") con el mixedema del adulto de Gull y con el cretinismo de los Alpes, sugiriendo que eran debidas a una deficiencia de la glándula tiroides ${ }^{(1-4)}$.

\section{La idea de la suplencia tiroidea}

En 1884, Moritz Schiff tuvo un relativo éxito en Ginebra al realizar injertos de tiroides caninos en perros tiroidectomiza$\operatorname{dos}^{(5)}$, y en 1886, el inglés Víctor Horsley -quien era reconocido por sus trabajos con injertos tiroideos- asignó como funciones de la tiroides la regulación del metabolismo de mucina y la de órganos hematopoyéticos ${ }^{(6)}$. Horsley ${ }^{(7)}$ había informado que los efectos de la tiroidectomía total en monos eran muy seguramente debidos a una pérdida de la función tiroidea (y no a una "asfixia crónica", como había sugerido Kocher). Recomendó que se realizaran injertos subcutáneos con tiroides de oveja, cosa que hicieron en 1890 Bettencourt y Serrano, en Lisboa ${ }^{(8)}$. El injerto colocado en uno de sus pacientes funcionó de inmediato, y los científicos describieron la mejoría lograda. El reconocido fisiólogo Gley, ese mismo año, publicó un informe sobre el tema ${ }^{(9)}$.

\section{El aporte de Murray}

Generalmente se adscribe a George Murray (figura 1) la primera experiencia, cuando -tres meses después de los portugueses- presentó un plan similar en la Sociedad Médica de Northumberland y Durham en 1891, siguiendo el consejo de Horsley, su profesor de pregrado. La propuesta fue recibida con escepticismo. En la publicación posterior informó que al inyectar periódicamente extractos glicerinados tiroideos de oveja en una paciente hipotiroidea, ésta mejoró de sus síntomas $^{(10,11)}$. Durante los 28 años que la paciente vivió hasta los 74 años con el tratamiento -inyectado inicialmente, por vía oral, después-recibió unos 5 litros de extracto tiroideo, procedente de 870 ovejas $^{(11)}$.

Tal vez esto es debido a que la publicación de este último fue hecha en el conocido British Medical Journal, mientras que la de los portugueses consistió en una breve nota que apareció en las actas de la sociedad de Lisboa, para luego publicarse en una revista más modesta.

Figura 1. Facsímil del libro de George Murray sobre Enfermedades de la Glándula Tiroides, año 1900.

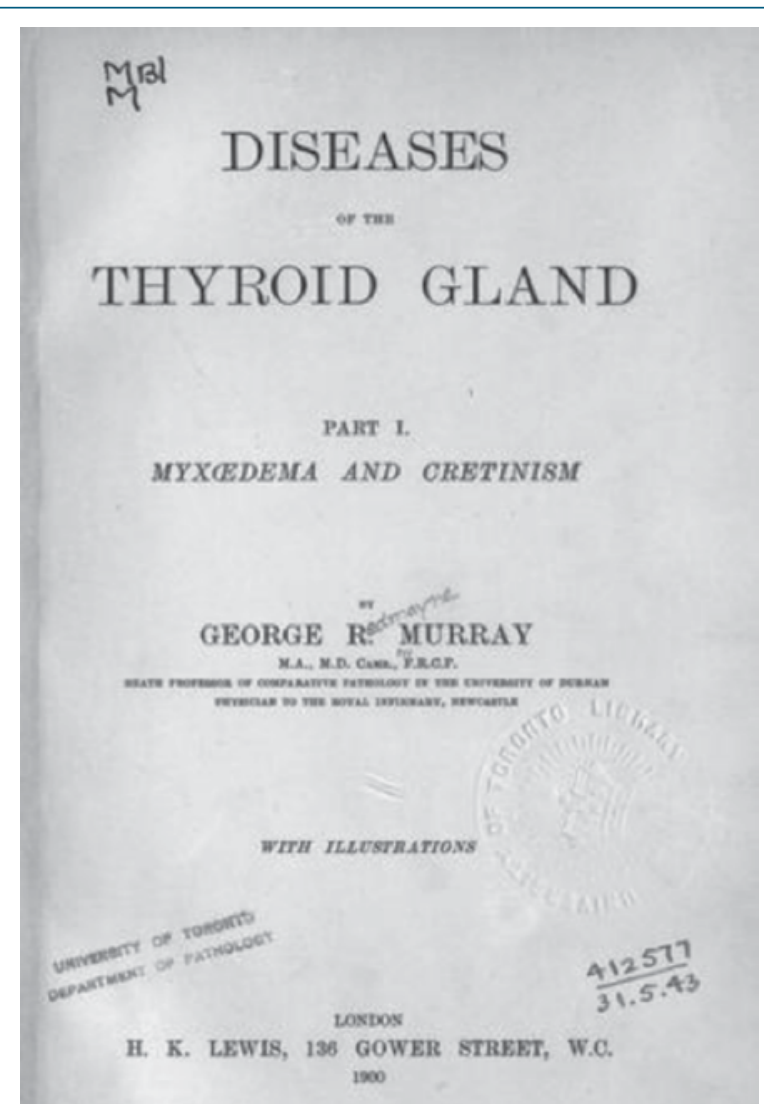


Murray y Horsley conocían -aunque no en detalle- lo hecho por los portugueses. El tiroides ovino lo consiguió el primero de una carnicería y de un lóbulo tiroideo sacó un extracto de 1,5 ml que inyectó por vía subcutánea a una paciente mixedematosa, para dárselo dos veces por semana. Tres meses después la paciente estaba mejor y había recibido el equivalente a 5 lóbulos de tiroides de oveja.

Poco después de la publicación de Murray, Héctor McKensie trató en 1892 a una mujer hipotiroidea durante unos meses, y describió todos los inconvenientes y efectos secundarios del tratamiento por vía subcutánea ${ }^{(12)}$. El mismo McKensie, y Fox -en Inglaterra- y Howitz, en Dinamarca, iniciaron entonces tratamientos por vía oral con buenos resultados y reconocieron los síntomas de la sobredosis. Se desmenuzaba tiroides fresco de oveja -obtenido en la carnicería- en pequeñas cantidades de brandy o jugo de carne, preparación con muy mal sabor. También intentaron darlo con mermelada, o con pasta de anchoas en un sándwich, diariamente. En 1893, el investigador danés fue el primero en recomendar tabletas de tiroides desecado, que para ese entonces comenzaron a producirse comercialmente ${ }^{(13)}$.

Murray -quién terminó pasando a sus enfermos a la vía oral- publicó más casos posteriormente, dos de los cuáles murieron súbitamente cuando estaban bastante bien.

Las series de casos no se hicieron esperar. Muy importantes fueron la de Cecil Beadles ${ }^{(14)}$ y la de Byrom Bramwell ${ }^{(15)}$, que incluyeron bastante información y dieron una guía para el tratamiento. El mixedema pasó de ser una patología exótica para convertirse en una entidad frecuente. Beadles ${ }^{(14)}$ informó que la apariencia de los pacientes cambiaba rápidamente con el tratamiento, se convertían en individuos sanos más jóvenes, con cantidades muy pequeñas de extracto tiroideo. Bramwell ${ }^{(15)}$ sugirió comenzar con dosis pequeñas con aumentos progresivos, para evitar complicaciones en ancianos y en enfermos coronarios o con enfermedad vascular, y advirtió que el tratamiento debía darse de por vida.

\section{La prueba del metabolismo basal}

En 1895, Magnus-Levy comprobó, por medidas del cambio gaseoso, que la administración de tiroides aumenta el consumo de oxígeno. El metabolismo basal se convirtió entonces, y durante muchas décadas, en la única prueba para medir la función tiroidea, reflejando la acción periférica de estas hormonas. Inicialmente se usaba para comparar los metabolismos de los diferentes animales. Este examen se basa en la correlación del consumo de oxígeno con el índice de masa corporal, sexo, edad, embarazo y otros factores. Como índice de actividad tiroidea fue popularizado por Boothby y también por Aub y DuBois y el tiroidólogo James Howard Means, quienes publicaron sus experiencias con pacientes hiper e hipotiroideos.

\section{La tiroxina: aportes de Kendall y Harington}

Edward C. Kendall (galardonado con el Nobel años después por su descubrimiento de la cortisona), aisló la tiroxina en su forma cristalina o pura, en el día de Navidad de $1914^{(20)}$. Lo hizo en la Clínica Mayo, a partir de un hidrolizado de 6.500 libras de glándulas tiroideas de cerdo. El trabajo fue publicado en el Journal of Biological Chemistry, refiriéndose al aislamiento del yodo que se encuentra en la glándula tiroides. Después de 10 años de arduo trabajo, Kendall y su grupo no pudieron identificar la estructura de la tiroxina, porque su conclusión de que se trataba del ácido triyohexahidroxi-indol-propiónico era errada. Había logrado sin embargo una proeza, pues además de anotar que $65 \%$ de su peso era yodo, estudió los efectos fisiológicos de la hormona ${ }^{(13)}$.

En 1921, George Barger -profesor de Química en Relación con la Medicina de la Universidad de Edinburgo- recomendó que se nombrara a Charles Harington (figura 2) como químico del Royal Infirmary de Edinburgo, donde él tenía un pequeño laboratorio que prestaba servicio a los clínicos y servía para la investigación. En 1922, Harington fue nombrado en el Colegio Universitario de Londres, y en 1926 determinó la estructura de la tiroxina y la sintetizó. El inglés consideró correctamente que se trataba del derivado tetrayodado de la tironina. Aunque él intentó producir esta hormona, tuvo dificultades para incorporar el yodo final en la molécula sintética, por lo que en 1927 consultó con Barger. Este propuso que usara el triyoduro de nitrógeno -compuesto muy inestable y explosivo- y de esta manera tuvo éxito ${ }^{(21,22)}$.

Figura 2. Sir Charles Harington

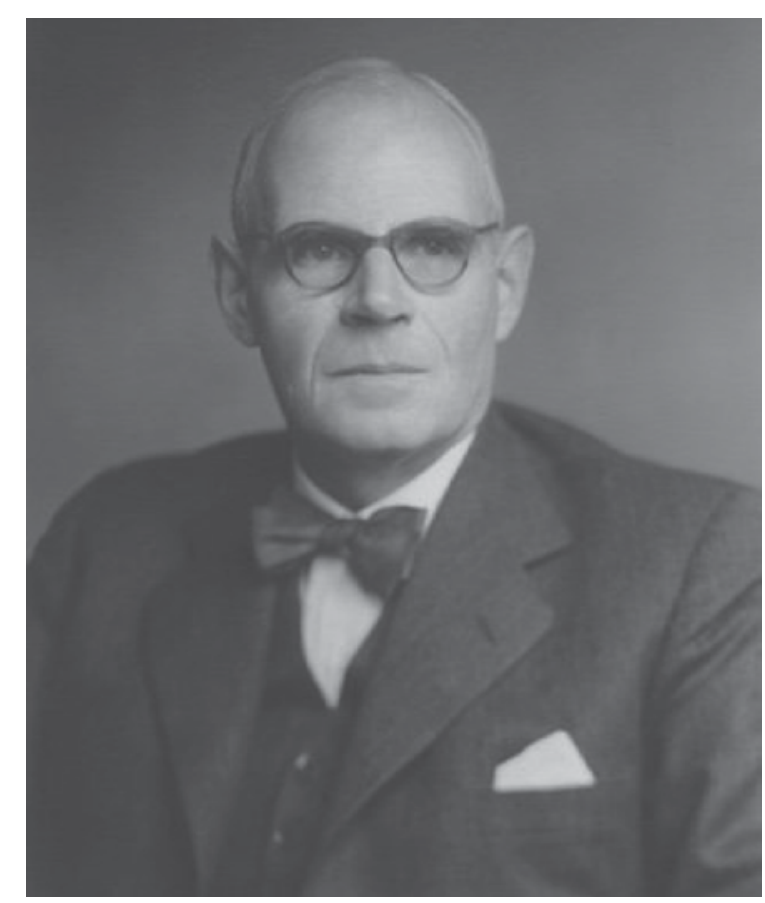

http://revistaendocrino.org/ 
Harington -citado por Amaro-Méndez ${ }^{(23)}$ - narra lo siguiente sobre la mayor dificultad que encontró para la síntesis: Cuando fue necesario reducir el doble enlace del compuesto en la penúltima etapa, todos los métodos empleados para reducciones de este tipo removían los átomos de yodo. La solución del problema fue algo así como un disparo en la oscuridad. Cuando le hablé de ello a un distinguido químico orgánico, su respuesta fue: Harington justed no debió haber tenido éxito de ese modo! Resultaba obvio que él -con mucho mayor conocimiento y experiencia-nunca habría intentado el experimento.

Tan pronto fue posible la síntesis de la tiroxina, el profesor David M. Lyon ensayó la hormona en sus pacientes del Hospital Real de Edimburgo. Arthur D. Hirschfelder -del mismo hospital escocés- nominó, en 1931, a Harington y a otros dos investigadores para el Premio Nobel. Aunque no se le otorgó, varios de sus exalumnos e investigadores del Instituto de Investigaciones Médicas -que dirigió entre 1942 y 1962- si fueron laureados (A.J.P. Martin -quien desarrolló la cromatografía líquida y de gas- recibió en 1952 el de Química; R.R. Porter -quien estudió la estructura de los anticuerpos- ganó en 1972 el de Medicina; J.W.Cornforth -que hizo estudios sobre la biosíntesis de los esteroides- ganó el de Química en 1975; Vincent Du Vigneaud -descubridor de la hormona antidiurética- ganó el de Química en 1955; A. Isaacs, descubridor del interferón en el Instituto dirigido por Harington- no lo ganó sin embargo).

Años más tarde, en 1952, Gross y Rosalind Pitt-Rivers identificaron la triyodotironina, la hormona que directamente actúa a nivel nuclear ${ }^{(24,25)}$. Esto fue posible gracias a nuevas tecnologías que permitían medir diminutas cantidades de yodo en los tejidos, al advenimiento del yodo radiactivo para investigación y al desarrollo de la cromatografía de papel, que permite identificar diferentes compuestos ${ }^{(26)}$.

\section{Suplencia con preparados naturales}

A pesar de estos aportes, una hormona tiroidea que pudiese comercializarse, tardó varias décadas. Inicialmente se necesitaban tres toneladas de tiroides de cerdo para aislar 33 gramos de tiroxina pura. Cuando la tiroxina se introdujo en el mercado por la casa Squibb, el precio de USD 350.oo/g no retribuía la inversión en su producción. Glaxo también había lanzado su tiroxina en 1949, época en que todavía se seguía utilizando el tiroides desecado como patrón de oro. Smith, Kline \& French (ahora GSK) comercializó la triyodotironina que -por vía intravenosa- se ha usado para el tratamiento del coma por mixedema. En los Estados Unidos se utilizó durante varias décadas el tiroides desecado, aunque en nuestro medio fue más popular la tiroglobulina ${ }^{(18,19)}$.

\section{Levotiroxina sintética para uso oral}

La producción de levotiroxina para uso terapéutico no fue una tarea fácil. Durante décadas debió esperarse un preparado de biodisponibilidad fiable. Aunque el desarrollo del radioinmunoanálisis por Yalow y Berson mejoró las posibilidades diagnósticas para el hipotiroidismo, solo con el advenimiento de la TSH ultrasensible (un método inmuno-radiométrico (IRMA) que utiliza dos anticuerpos monoclonales anti-TSH), se logró la determinación de niveles de TSH compatibles con hipotiroidismo subclínico (mandando al olvido la prueba de estimulación con TRH) o con hipertiroidismo, permitiendo así la titulación individual de la dosis de levotiroxina ${ }^{(27)}$.

\section{¿Por qué levotiroxina y no 3’5'triyodotironina?}

El posterior descubrimiento de las deyodasas hepáticas demostró que el hígado es el principal órgano endocrino productor de T3 bioactiva, además encargado de su metabolización posterior a T3 reversa y a otros metabolitos. Con esto quedó claro por qué la levotiroxina es la hormona de suplencia ideal ${ }^{(28)}$.

Algunos pacientes continúan quejándose de fatiga, a pesar de que se obtiene el nivel ideal de TSH con la monoterapia tiroxínica. Como soporte para aquellos partidarios de agregar T3, se descubrió un polimorfismo en el gen D2 (Thr92Ala) en enfermos con una activación reducida de T4 a T3 en el tejido muscular y en la glándula tiroides, trastorno que se asocia con obesidad y alteraciones en la retroalimentación hipofisiaria $^{(29)}$. Éste y otros hallazgos que vendrán nos indican que no ha llegado el final de la historia de la suplencia tiroidea.

\section{El problema de la estabilidad}

Aunque la molécula de levotiroxina llevaba ya muchos años descubierta, en 2001 la FDA solicitó a Knoll (adquirida luego por Abbott) que reiniciara todas las etapas de registro sanitario de su levotiroxina con la marca "Synthroid". En realidad esta tiroxina (como otras marcas y las genéricas) han tenido problemas de fabricación, bioequivalencia, eficacia en ciertos lotes, inestabilidad. Las tabletas pierden potencia en las estanterías de las farmacias, incluso antes de que llegue la fecha de vencimiento. Han reformulado las tabletas, han agregado nuevos excipientes y han hecho cambios en los colorantes ${ }^{(30)}$. Estas dificultades nos indican que -aunque el manejo de la levotiroxina es delicado- siguiendo ciertos parámetros es posible obtener resultados satisfactorios. Aunque es difícil de probar, muchos escándalos que de cuando en vez rodean a la tiroxina (y a otras drogas) posiblemente se deban a una histeria colectiva ${ }^{(31)}$. 


\section{Referencias}

1. Semon F. In discussion of 'A typical case of myxoedema' by FD Drewitt in the Proceedings of the Clinical Society of London. BMJ 1883;ii:1072-4.

2. Clinical Society of London Report of a committee nominated December 14 1883, to investigate the subject of myxoedema. Trans Clin Soc Lond 1888; 21 Suppl.

3. Medvei VC. The History of Clinical Endocrinology: a comprehensive account of endocrinology from earliest times to the present day. Carnforth: Parthenon; 1993.

4. Jácome-Roca A. El descubrimiento del hipotiroidismo. Rev Col Endocrinol Diab \& Metab. 2017; vol.4, No. 4

5. Schiff M. Résumé d'une nouvelle série d'expériences sur les effets de l'ablation des corps thyroîdes. Revue Médicale de la Suisse Romande 1884;4:425-45.

6. Horsley V. On the function of the thyroid gland. Proc Roy Soc Lond 1885;38:5-7.

7. Horsley V. Note on a possible means of arresting the progress of myxoedema, cachexia strumipriva, and allied diseases. BMJ 1890;i:287-8.

8. Bettencourt R, Serrano JA. Un cas de myxoedème traité par la greffe hypodermique du corps thyroïde d'un mouton. La Semaine Médicale 1890;10:294

9. Gley E. Note préliminaire sur les effets physiologiques du suc de diverses glandes et en particulier du suc extraits de la glande thyroîde. Comptes Rendus de la Societé de la Biologie (Paris) 1891;43:250-1.

10. Murray GR. Note on the treatment of myxoedema by hypodermic injections of an extract of the thyroid gland of a sheep. BMJ 1891;ii:796-7.

11. Murray GR. The life-history of the first case of myxoedema treated by thyroid extract. BMJ 1920;i:359-60.

12. Mackenzie HWG. A case of myxoedema treated with great benefit by feeding with fresh thyroid glands. BMJ 1892;ii:940-1 (Citado por Slater).

13. Jácome-Roca A. Historia de las Hormonas. Academia Nacional de Medicina 2005. Pp. 91.

14. Beadles CF. The treatment of myxoedema and cretinism, being a review of the treatment of these diseases with the thyroid gland, with a table of $100 \mathrm{pub}$ lished cases. J Mental Science 1893;39:343-55, 509-36 (citado por Slater).

15. Bramwell B. The thyroid treatment of myxoedema and sporadic cretinism, with notes of twenty-three cases of myxoedema and five cases of sporadic cretinism, treated by thyroid extract. Edinburgh Hosp Rep 1895;3:116-249 (citado por Slater)
16. Slater S. The discovery of thyroid replacement therapy. Part I. In the beginning. J R Soc Med. 2011; 104(1):15-8.

17. Slater $\mathrm{S}$. The discovery of thyroid replacement therapy. Part II. The critical nineteen century. J R Soc Med. 2011; 104(2):59-63.

18. Slater $\mathrm{S}$. The discovery of thyroid replacement therapy. Part 3: A complete transformation. J R Soc Med. 2011; 104(3): 100-106.

19. McAninch EA, Bianco AC. The History and Future of Treatment of Hypothyroidism. Ann Intern Med. 2016;164(1):50-6.

20. Kendall EC. The isolation in crystalline form of the compound containing iodin, which occurs in the thyroid: its chemical nature and physiologic activity. J Am Med Ass 1915; 64:2042-3 (Este artículo volvió a publicarse con comentarios, en JAMA. 1983 Oct 21; 250 (15):2045-6.

21. Harington CR. Chemistry of thyroxine. II: Constitution and synthesis of desiodo-thyroxine. Biochem J 1926;20:300-13.

22. Harington CR, Barger G. Chemistry of thyroxine. III: Constitution and synthesis of thyroxine. Biochem J 1927; 21:169-83 33.

23. Amaro-Méndez S. Breve historia de la endocrinología. Editorial científicotécnica, La Habana, 1975.

24. Gross J, Pitt-Rivers R. The identification of 3:5:3' -L-triiodothyronine in human plasma. Lancet 1952;i:439-41.

25. Gross J, Pitt-Rivers R. 3:5:3' Triiodothyronine. I: Isolation from thyroid gland and synthesis. Biochem J 1953;53:645.

26. Galton VA. The history of 3, 5, 3' triiodothyronine. Thyroid 2013; 23(1).

27. Seth J, Kellet HA, Caidwel G, et al. A sensitive immunoradiometric assay for serum thyroid stimulating hormone: a replacement for the thyrotropin releasing hormone teat? Br Med J 1984; 289:1334-6.

28. Bianco AC, Kim BW. Deiodinases: implications of the local control of thyroid hormone action. J Clin Invest. 2006; 116 (10):2571-9.

29. Wartofsky L. Combination L-T3 and L-T4 therapy for hypothyroidism. Curr Opin Endocrinol Diabetes Obes. 2013; 20(5):460-6.

30. CDER Guidance Document. Levothyroxine Sodium Products Enforcement of August 14, 2001-Compliance Date and Submission of New Applications. U.S. Food and Drug Administration. Available at: http://www.fda.gov/cder/ guidance $/ 4647 \mathrm{fnl} . \mathrm{htm}$.

31. Jácome-Roca A. Enfermedad psicogénica masiva después de una campaña de vacunación. Episodios anteriores y aproximación al caso colombiano. Medicina, 2014; 36 (3): 269-273. 